\title{
Erratum to: Different mosquito species host Wickerhamomyces anomalus (Pichia anomala): perspectives on vector-borne diseases symbiotic control
}

\author{
Irene Ricci - Michela Mosca - Matteo Valzano - Claudia Damiani • \\ Patrizia Scuppa · Paolo Rossi - Elena Crotti - Alessia Cappelli - Ulisse Ulissi • \\ Aida Capone - Fulvio Esposito - Alberto Alma - Mauro Mandrioli • \\ Luciano Sacchi • Claudio Bandi · Daniele Daffonchio • Guido Favia
}

Published online: 28 May 2014

(C) Springer International Publishing Switzerland 2014

\section{Erratum to: Antonie van Leeuwenhoek (2011) 99:43-50}

$$
\text { DOI 10.1007/s10482-010-9532-3 }
$$

Subsequent to the publication of the above paper it has been brought to our attention that there are errors of clarity in the discussion of the work of Gibson and Hunter (2005).

Firstly, where the authors state (p. 47) that "...the insect gonads are characterized by a thick system of tracheal trunks that could represent an advantage for meeting oxygen demands (Gibson and Hunter 2005)" the authors should have stated that it is actually the diverticulum (associated with the gastrointestinal

The online version of the original article can be found under doi:10.1007/s10482-010-9532-3.

I. Ricci - M. Mosca - M. Valzano - C. Damiani .

P. Scuppa - P. Rossi - A. Cappelli · U. Ulissi .

A. Capone · F. Esposito - G. Favia ( $\square)$

Scuola di Bioscienze e Biotecnologie, Università degli

Studi di Camerino, 62032 Camerino, Italy

e-mail: guido.favia@unicam.it

E. Crotti · D. Daffonchio

Dipartimento di Scienze e Tecnologie Alimentari e Microbiologiche, Università degli Studi di Milano, 20133 Milan, Italy

\section{A. Alma}

Dipartimento di Valorizzazione e Protezione delle Risorse Agroforestali, Università degli Studi di Torino, 10095 Turin, Italy tract) of lacewings that has larger tracheal trunks likely to meet the needs of symbiotic yeasts (as first discovered by Hagen et al. 1970). Ricci et al. point out that mosquito gonads (particularly ovary in pre-gravid females) show an evident tracheal system with closely wound terminal tracheoles (Bruce-Chwatt 1985).

Secondly, where the authors state (p. 47) "This kind of transmission [transovariole] of yeasts in insects has been hypothesised rarely, as in the case of the lacewings Chrysoperla (Gibson and Hunter 2005)..." it should be clarified that Gibson and Hunter (2005) do not hypothesize transovariole transmission of yeasts in lacewings. Rather, Gibson and Hunter (2005) find suggestive evidence that vertical transmission occurs via smearing on external egg surfaces where larvae consume symbionts upon hatching. Ricci et al. wish here to clarify that their original text: "This kind of

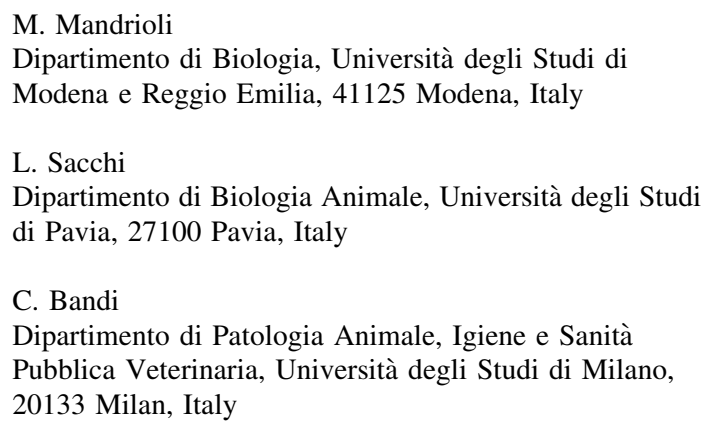


transmission of yeasts in insects has been hypothesised rarely" meant vertical transmission.

\section{References}

Bruce-Chwatt LJ (1985) Essential malariology, 2nd ed. W. Heinemann Medical Books
Gibson CM, Hunter MS (2005) A reconsideration of the role of yeast associated with Chrysoperla lacewings. Biol Control 32:57-64

Hagen KS, Tassan RL, Sawall EF Jr (1970) Some ecophysiological relationships between certain Chrysopa, honeydews and yeasts. Bull Lab Entomol Agric Fil Silv 28:113-134 